\title{
Eefect of Tenure of Service on Job Stress Andnurse-Physician Collaboration among Nurses and Doctors
}

\author{
Olatunji, S.O., Mokuolu, B.O. \\ Department of Psychology, Faculty of the Social Sciences, Ekiti State University, Nigeria \\ Department of Psychology, Faculty of the Social Sciences, Ekiti State University, Nigeria
}

\begin{abstract}
This study examined the role that experience plays in nurse-physician collaboration and how this experience affects the level of job stress that entails among the health workers. 191 health workers comprising of 102 nurses and 89 physicians were involved, this include 26 female and 63 male physicians, and 68 female and 34 male nurses. Perceived stress scale by Cohen (1983) and Satisfaction about Care Decisions developed by Baggs (1994) were employed as measures of job stress and nurse-physician collaboration respectively. The result showed that tenure of service has a significant effect on job stress and collaboration among nurses, workers with greater than ten years of service reporting higher level of collaboration and lower level of job stress compared with their counterparts of fewer years of experience. Collaborative practice is suggested between doctors and nurses at all cadres, and mentoring should be encouraged among the senior and the junior health workers so as to bring confidence on the job and consequently reduce the experience of stress.
\end{abstract}

\section{Introduction:}

Experience is said to be the best teacher and the knowledge that experience impacts is such that cannot be underestimated. Work place experience is not left out especially among health workers. The period when a worker holds an important job is significant in his /her ability to cope with stress and challenges. It also influences collaborative practice among workers. William, Michie,\&Pattani (1998) indicated that most sources of stress, that is workload, leadership/management issues, professional conflicts and emotional demands of caring, have been identified consistently by nurses for many years and it is not surprising that they relate to the main generic characteristics of practice. Although stress is experienced by everybody at one time or the other, Cordon (1997) identified it as a variety of negative feelings and reactions that accompany threatening or challenging situations.

Dollard, Winifielf and De jonge (2000) opined that workers who are experiencing stress often become alienated from their co-workers and may suffer from headache, exhaustion, back problems and insomnia apart from being job dissatisfied. Alienation at work place can lead to stress as Thiots (1995) in his study discovered that alienation has a positive relationship with job stress.

According to Adebayo (2001), the theory of interpersonal behaviour formulated by Schutz (1955) explains the three possible orientation manners in interpersonal relations, this include inclusion, control and affection. Inclusion means the need to associate with others while control is the need of individuals or groups to dominate or be dominated and lastly, affection is the need to have close personal and affectionate feelings between two individuals or two groups. This theory of Fundamental interpersonal relations orientation can be used to explain collaborative practice. For example, physicians and nurses may not be compatible in their interaction. If physicians have a high need to control and nurses have a low need for being controlled, or if nurses have a high need for inclusion with physician in decision making and physician have a low need for inclusion with nurses, these two needs would definitely bring about incompatibility between these two groups and consequently bring about job dissatisfaction among nurses. Nurses may feel that they are being subservient while physicians are being dominant in decision making. Thus nurses and physicians tend to perceive the value and need for collaboration differently.

\section{Methods}

The purpose of this study precisely is to examine the effect of tenure of service on nurse/physician collaboration among nurses and physicians, to also examine the effect of tenure of service on the experience of job stress and which of the professions is more affected out of the two considered.

In order to achieve this, 191 participants from Federal medical centres in Nigeria were involved;this includes 89 doctors and 102 nurses randomly drawn from different sections. This is made up of 26 female doctors and 63male doctors, 68 female nurses and 34 male nurses.

The instruments used include perceived stress scale by Cohen (1983). It is a ten items questionnaire with a five-point scale: $0=$ never, $1=$ almost never, $2=$ sometimes, $3=$ fairly often $4=$ very often. The higher 
the score of an individual on this scale,the higher the perceived stress. A local norm of 18.84 was obtained for Nigerian respondents.

The second instrument, Collaboration and Satisfaction about Care Decisions developed by Baggs (1994) was employed to measure nurse/physician collaboration. It has 8 items with 0.90 reliability coefficient. A local norm of 27.75 was obtained for Nigerian respondents.

Single items were used to measure the job status (i.e. either a physician or a nurse), tenure of service indicated as years spent on the job.

Procedure:The consent of the authorities of the medical centres was sought, and that of the nurses and physicians before the copies of the questionnaire were distributed among theparticipantsfrom all the units of the medical centres. Some of the questionnaires were filled and returned immediately while some requested that the researcher should come back later to retrieve it.

\section{Results:}

Table 1: Cross tabulation ofJob Stress, Nurse/Physician Collaboration and Tenure of service among health workers

\begin{tabular}{|c|c|c|c|c|}
\hline & \multicolumn{3}{|c|}{ Tenure of service } & \multirow[b]{2}{*}{ Total } \\
\hline & $<5$ years & $5-10$ years & $>10$ years & \\
\hline $\begin{array}{lr}\text { Job Stress } & \begin{array}{r}\text { High } \\
\text { Low }\end{array} \\
\end{array}$ & $\begin{array}{l}112(97 \%) \\
3(3 \%)\end{array}$ & $\begin{array}{l}13(25 \%) \\
38(75 \%)\end{array}$ & $\begin{array}{l}1(4 \%) \\
24(96 \%)\end{array}$ & $\begin{array}{l}126(66 \%) \\
65(34 \%)\end{array}$ \\
\hline $\begin{array}{l}\text { Collaboration } \\
\text { No collaboration }\end{array}$ & $\begin{array}{l}23(20 \%) \\
92(80 \%)\end{array}$ & $\begin{array}{l}29(57 \%) \\
22(43 \%)\end{array}$ & $\begin{array}{l}18(72 \%) \\
7(28 \%)\end{array}$ & $\begin{array}{l}70(37 \%) \\
121(63 \%)\end{array}$ \\
\hline Total & $115(100 \%)$ & $51(100 \%)$ & $25(100 \%)$ & $191(100 \%)$ \\
\hline
\end{tabular}

Ability to handle stress in workplace is been developed over years of experience, as the result in table 1 shows that only one (4\%) out of 25 physicians and nurses who have stayed on the job above ten years actually reported high stress, compared with those that have spent less than 5 years where $112(97.39 \%)$ out of 115 reported high job stress.

Also 18 (72\%) out of 25 ofthe health workers have stayed on the job above ten years reported high collaboration compared with those below 5years where $92(80 \%)$ out of 115 reported low collaboration.

Table 2: Cross tabulation of Job Stress, Nurse/Physician Collaboration and job status

\begin{tabular}{|l|l|l|l|}
\hline \multirow{2}{*}{ Job Stress High } & Status & Nurses & \\
\cline { 2 - 4 } & Doctors & $86(84.3 \%)$ & $126(66 \%)$ \\
Low & $40(45 \%)$ & $16(15.7 \%)$ & $65(34 \%)$ \\
\hline Collaboration & $49(55 \%)$ & & $70(37 \%)$ \\
No collaboration & $59(66 \%)$ & $11(10 \%)$ & $121(63 \%)$ \\
\hline Total & $30(34 \%)$ & $91(89 \%)$ & $191(100 \%)$ \\
\hline
\end{tabular}

A higher percentage of Nurses $(84 \%)$ reported that they are stressed; a higher percentage of Nurses $(63 \%)$ reported that they do not enjoy collaboration

Table 3: One way ANOVA summary table showing the effect of tenure of service on job satisfaction among nurses and doctors.

\begin{tabular}{|c|c|c|c|c|c|c|c|c|}
\hline \multirow[t]{2}{*}{ Variables } & \multicolumn{2}{|c|}{$\begin{array}{l}<5 \text { Years } \\
n=115\end{array}$} & \multicolumn{2}{|c|}{$\begin{array}{l}\text { 5-10 Years } \\
n=51\end{array}$} & \multicolumn{2}{|c|}{$\begin{array}{l}>10 \text { Years } \\
n=25\end{array}$} & \multirow[t]{2}{*}{ Group effect } & \multirow[t]{2}{*}{$\mathrm{P}$} \\
\hline & $\chi$ & SD & $\chi$ & SD & $\chi$ & SD & & \\
\hline N/P Collaboration & 18.71 & 18.52 & 34.25 & 21.85 & 42.24 & 19.15 & $\mathrm{~F}(2,190)=21.19$ & $<.01$ \\
\hline Job stress & 29.64 & 6.01 & 15.00 & 9.02 & 6.60 & 4.27 & $\mathrm{~F}(2,190)=163.71$ & $<.01$ \\
\hline
\end{tabular}

There is a significant effect of tenure of service on nurse/physician collaboration, the means show that the health workers that have spent more than 10 years reported highest level of collaboration. There is also a significant effect of tenure of service on the level of stress they reported.

Scheffepost hoc analysisreported a significant difference in the N/P collaboration between the workers with $<5$ years of experience and those with 5-10years and above10 years, but no significant difference between 510 years and above10 years; and also a significant difference in the level of stress between the workers with 
$<5$ years of experience and those with 5-10years and above10 years, but no significant difference between 510 years and above10 years

Table 4: Descriptive Statistics showing the mean and standard deviation of NP collaboration and stress among Doctors and Nurses at the different categories of tenure of service

\begin{tabular}{|c|c|c|c|c|c|c|}
\hline \multirow[b]{2}{*}{ Tenure of service } & \multirow[b]{2}{*}{ status } & \multirow[b]{2}{*}{$\mathrm{N}$} & \multicolumn{2}{|c|}{ NP Collaboration } & \multicolumn{2}{|l|}{ Stress } \\
\hline & & & Mean & $\begin{array}{l}\text { Std. } \\
\text { Deviation }\end{array}$ & Mean & $\begin{array}{l}\text { Std. } \\
\text { Deviation }\end{array}$ \\
\hline \multirow[t]{3}{*}{$<5$ years } & Doctors & 39 & 34.95 & 22.09 & 29.41 & 6.05 \\
\hline & Nurses & 76 & 10.38 & 8.15 & 29.76 & 6.04 \\
\hline & Total & 115 & 18.71 & 18.52 & 29.64 & 6.02 \\
\hline \multirow[t]{3}{*}{$5-10$ years } & Doctors & 32 & 44.91 & 16.39 & 11.56 & 7.07 \\
\hline & Nurses & 19 & 16.32 & 17.94 & 20.79 & 9.16 \\
\hline & Total & 51 & 34.26 & 21.85 & 15.00 & 9.02 \\
\hline \multirow[t]{3}{*}{$>10$ years } & Doctors & 18 & 39.56 & 19.35 & 6.11 & 3.59 \\
\hline & Nurses & 7 & 49.14 & 18.14 & 7.86 & 5.82 \\
\hline & Total & 25 & 42.24 & 19.15 & 6.60 & 4.27 \\
\hline \multirow[t]{3}{*}{ Total } & Doctors & 89 & 39.46 & 19.94 & 18.28 & 11.73 \\
\hline & Nurses & 102 & 14.15 & 14.92 & 26.59 & 9.07 \\
\hline & Total & 191 & 25.94 & 21.52 & 22.72 & 11.17 \\
\hline
\end{tabular}

Table 5: $3 \times 2$ ANOVA Table showing the effect of Tenure of service and Job status on N/P Collaboration

\begin{tabular}{|l|l|l|l|l|l|}
\hline Source & Sum of Squares & df & Mean Square & F & Sig. \\
\hline Tenure of service & 8594.17 & 2 & 4297.09 & 17.29 & .000 \\
Status & 5912.21 & 1 & 5912.21 & 23.78 & .000 \\
Tenure of service * status & 5711.46 & 2 & 2855.73 & 11.49 & .000 \\
Error & 45989.96 & 185 & 248.59 & & \\
Total & 87928.37 & 190 & & & \\
\hline
\end{tabular}

$2 \mathrm{X} 3$ ANOVA shows the Joint effect of job status and tenure in service on nurse-physician collaboration as $\mathrm{F}(2,190)=11.49, \mathrm{p}<.05$. Scheffe shows that there is no significant difference in the collaboration reported by the doctors across the categories of tenure of service, but among the nurses, there is a significant difference between nurses at $<5$ years and $>10$ Years of service; and between 5-10 years and $>10$ years.

Table 6: 3x2 ANOVA Table showing the effect of Tenure of service and Job status on N/P Stress

\begin{tabular}{|l|l|l|l|l|l|}
\hline Source & Sum of Squares & df & Mean Square & F & Sig. \\
\hline Tenure of service & 11859.06 & 2 & 5929.53 & 144.21 & .000 \\
Status & 399.49 & 1 & 399.49 & 9.72 & .002 \\
Tenure of service * status & 650.78 & 2 & 325.33 & 7.91 & .001 \\
Error & 7606.84 & 185 & 41.12 & & \\
Total & 23688.73 & 190 & & & \\
\hline
\end{tabular}

$2 \mathrm{X} 3$ ANOVA shows the Joint effect of job status and tenure in service on job stress as $F(2,190)=7.91, \mathrm{p}<.05$. Scheffe Post hoc analysis comparing stress among the categories of tenure of service shows that there is no significant difference in the stress reported by the physicians in the $<5$ years and 5-10 years category of tenure of service, but among the nurses, there is a significant difference across the years of tenure of service.

\section{Discussion}

Three major hypotheses were tested, the hypothesis that perceived job stress will be affected by tenure of service was confirmed, as the result shows that the health workers that have spent more than 10 years in service do not perceive the job to be stressful (only $1 \%$ reported being stressed). Unlike those that have spent less than 5 years where $97 \%$ of them perceived the job as been stressful with the mean score of 29.64 (SD 6.05). This is in line with the findings of Cherniss (1986) in a research carried out on young professionals that are new on the job. He established that as tenure of service increases, there was reduction in the tendency to have burnout.

The second hypothesis that there will be a significant effect of tenure of service on nurse/physician collaboration was also supported. The researcher found out that the enjoyment of collaboration betweennurses and doctors depends on the tenure of service. Kurtz 1980). Observed that physicians would prefer not to be interactive and therefore avoid group involvement. 
Researchers have shown that where interaction with others to achieve individual and group goals is encouraged, employees are more committed to organisation. (Dimegho, Piatek, Korber, Barett, Ducharm, Lucas, piermont et al (2005).

\section{Conclusion}

When the tenure of service increases, stress is low and vice versa. In the same vein, collaboration between nurses and doctors is possible when nurses have spent a reasonable length of years in service. Doctorsdon't collaborate with inexperienced nurses.

\section{Recommendation:}

Collaborative practice is suggested between doctors and nurses at all cadres, and mentoring should be encouraged among the senior and the junior health workers so as to bring confidence on the job and consequently reduce the experience of stress.

Seminars and workshop on stress reduction must be targeted at less experience nurses and doctors.

\section{References}

[1] William, S., Michie, S., and Pattani, S. (1998).Improving the health of the NHS workforce: report of the partnership on the health of the NHS workforce.Nuffield Trust London UK.

[2] Dolland, m., Winefielf,A., De Joge,J.(2000). Psychological job starin and productivity in human service workers: a test of the demand control support model. Journal of occupational and organisational psychology, 73:501-511.

[3] Thoits, P. (1995). Stress, coping and social support processes: where we are? What next? Journal of health and social behaviour, 36(1) 53-79.

[4] Adebayo S.O. (2001). Social psychology of ethnic group relations in Nigeria.A publication of psychomotor communication; Lagos pp24-38.

[5] Schutz, W.C. (1955). What makes group productive. Human Relations 8,429-465.

[6] Cohen S., Kamarck. T., \&Mermelstein, R. (1983).A global measure of perceived stress.Journal of health and social behaviour. 24, 386-396

[7] Baggs, J.G. (1994). Development of an instrument to measure collaboration and satisfaction about care decisions.Advance Journal on Nurses 20, 176-182.

[8] Cherniss, C. (1986). Staff Burnout, Job Stress in Human Service. Beverly Hills, CA: sage

[9] Kurtz, M.W. (1980). A behavioural profile of physician managerial roles, in R. Schenke, (ed). The physician in management. Washington DC: Artisan, 33-34

[10] Di Megho,K., Padula, C., Piatetek, C., KorberS.,Barrett, A., Ducharm,M., Lucas, S., Piemont,N., Joyal,E., DeNichola, V. and Carry,K. (2005). Group cohesion and nurse satisfaction.Examination of a team-building approach. Journal of Nursing Administration, 35(3): 110-120 